\title{
Are the long-term outcomes of percutaneous ablation for clinical stage T1 renal tumors similar to those of partial nephrectomy?
}

\author{
Roy Mano ${ }^{1,2}$, A. Ari Hakimi \\ ${ }^{1}$ Department of Urology, Tel-Aviv Sourasky Medical Center, Sackler School of Medicine, Tel-Aviv University, Tel Aviv-Yafo, Israel; ${ }^{2}$ Urology Service, \\ Department of Surgery, Memorial Sloan Kettering Cancer Center, New York, NY, USA \\ Correspondence to: Roy Mano, MD. Department of Urology, Tel-Aviv Sourasky Medical Center, 6 Weizmann Street, Tel Aviv-Yafo, Israel. \\ Email: roymano78@gmail.com. \\ Provenance: This is an invited article commissioned by the Section Editor Dr. Xiao Li, MD (Department of Urology, Jiangsu Cancer Hospital \& \\ Jiangsu Institute of Cancer Research \& Nanjing Medical University Affiliated Cancer Hospital, Nanjing, China). \\ Comment on: Andrews JR, Atwell T, Schmit G, et al. Oncologic Outcomes Following Partial Nephrectomy and Percutaneous Ablation for cT1 Renal \\ Masses. Eur Urol 2019;76:244-51.
}

Submitted Aug 16, 2019. Accepted for publication Aug 28, 2019.

doi: 10.21037/atm.2019.08.106

View this article at: http://dx.doi.org/10.21037/atm.2019.08.106

A better understanding of the natural history of small renal masses and the adverse effects of radical nephrectomy on long term renal function and subsequent morbidity and mortality led to a surge in the use of nephron sparing surgery and surveillance for the treatment of clinical stage T1 renal masses (1-3). Nephron sparing treatment options include predominantly partial nephrectomy $(\mathrm{PN})$, however reports have shown the feasibility of percutaneous thermal ablation methods, including cryoablation and radiofrequency ablation (RFA), as possible alternatives (4). Initially used for patients who were unfit for surgery, the indications for these techniques have expanded to include a larger group of patients with small renal masses that are amendable to complete ablation $(5,6)$. While percutaneous ablative therapies are less invasive and result in superior functional outcomes compared to radical nephrectomy, it is uncertain whether they provide equivalent oncologic outcomes (7-9). To date, thermal ablative techniques were not compared to $\mathrm{PN}$ in a randomized prospective manner. The CONSERVE trial comparing PN with thermal ablation was terminated early due to poor accrual, and an ongoing trial (Clinicaltrials.gov identifier: NCT03094949) has not resulted yet (10). With the lack of randomized prospective studies comparing the oncological and functional outcome of ablative treatments and PN, current guidelines rely on non-randomized studies which are limited mostly by selection bias and a relative short followup which may not be sufficient to show differences in oncological outcomes (11-15).

In the current retrospective analysis, Andrews et al. compared local recurrence free survival, metastatic free survival and cancer-specific survival of $\mathrm{PN}$ and percutaneous ablation using either RFA or cryoablation for a large group of 1,798 patients treated at the Mayo Clinic for a cT1N0M0 renal mass (16). Median follow-up for the cohort was above 6 years. Among 1,422 patients treated for a cT1a tumor, $\leq 4 \mathrm{~cm}$ in diameter, 1,055 underwent PN, $180 \mathrm{RFA}$ and 187 cryoablation. No significant differences were found when comparing PN to either RFA or cryoablation on all evaluated outcomes with reported 5 -year CSS rates of 99\%, $96 \%$ and $100 \%$ for PN, RFA and cryoablation, respectively. Within the subgroup of 376 patients with cT1b tumors, between 4 to $7 \mathrm{~cm}$ in diameter, no significant difference was found when comparing $\mathrm{PN}(\mathrm{n}=324)$ and cryoablation $(\mathrm{n}=52)$; however, cancer related death after cryoablation was more common with a 5 -year CSS rate of $91 \%$ compared to $98 \%$ in patients treated with $\mathrm{PN}$ (16).

Previous studies comparing the oncologic outcomes of PN and percutaneous ablation were limited by the heterogeneity of the cohorts evaluated, selection bias, and relatively short follow-up periods. The current study, a large single center study with long follow-up, concluded that for patients with a cT1a tumor, clinically relevant differences in treatment outcomes are unlikely. While these results support the role of thermal ablation for cT1a tumors, they were obtained with substantial patient selection as evident 
by the different numbers of patients treated in each group and significant differences in patient characteristics between the treatment groups including younger age and lower Charlson comorbidity score among patients who underwent PN. In addition, overall survival rates of patients who underwent RFA and cryoablation were significantly lower than those of patients treated with PN, consistent with the older age and higher rate of comorbidities in the groups treated with ablation. The authors did not report additional reasons for selecting patients to receive a certain treatment; however previous studies suggest that patients treated with ablative therapies for tumors with a higher RENAL nephrometry score suffer a higher rate of adverse outcomes and may be less suitable for ablative procedures $(17,18)$. Camacho et al. reported that a RENAL nephrometry score $>8$ significantly predicted early tumor recurrence and complications after percutaneous ablative therapy for stage T1a RCC (17). Similarly, Schmit et al. found that patients with local recurrence and major complications after ablation were more likely to have a higher RENAL score (18). The selection bias, apparent in the current as well as previous studies, emphasizes the importance of conducting a prospective randomized comparison in order to truly understand the difference in treatment outcome when treating patients with cT1a renal tumors. Nevertheless, the similar long-term oncologic outcome suggests that with appropriate selection, thermal ablation may have a role in treating patients with renal masses less than $4 \mathrm{~cm}$ in size.

The conclusions of the study are less definitive for patients with $\mathrm{cT} 1 \mathrm{~b}$ tumors. A previous study looking at patients with $\mathrm{cT} 1 \mathrm{~b}$ tumors treated with cryoablation has shown a significant benefit to the use of PN with regards to local recurrence (11). While not statistically significant, in the current study, the outcome for patients treated with cryoablation was inferior to that of PN. As stated in the conclusions, future studies should evaluate the role of ablative treatments in this group of patients.

Considering the results of the current as well as previous studies, ongoing efforts should focus on optimizing the treatment for each individual patient, balancing between the oncologic and functional outcomes while considering the patients age and comorbidities and the tumor characteristics. A better understanding of the tumor's molecular features may aid in this decision process. A recent report by Manley et al. showed that patients with small renal masses that harbor a $K D M 5 C$ mutation have inferior survival from either recurrence or death of their disease (19).
Since patients who undergo ablation are recommended to have a renal mass biopsy before treatment-in the future, molecular characteristics of the tumor may guide us regarding the optimal treatment for this group of patients (10).

\section{Acknowledgments}

Funding: This work was supported by The Sidney Kimmel Center for Prostate and Urologic Cancers; and the National Institutes of Health/National Cancer Institute Cancer Center Support Grant P30 CA008748.

\section{Footnote}

Conflicts of Interest: The authors have no conflicts of interest to declare.

Ethical Statement: The authors are accountable for all aspects of the work in ensuring that questions related to the accuracy or integrity of any part of the work are appropriately investigated and resolved.

\section{References}

1. Huang WC, Atoria CL, Bjurlin M, et al. Management of Small Kidney Cancers in the New Millennium: Contemporary Trends and Outcomes in a PopulationBased Cohort. JAMA Surg 2015;150:664-72.

2. Huang WC, Levey AS, Serio AM, et al. Chronic kidney disease after nephrectomy in patients with renal cortical tumours: a retrospective cohort study. Lancet Oncol 2006;7:735-40.

3. Doolittle J, Piotrowski J, Zuk K, et al. Evolving Trends for Selected Treatments of T1a Renal Cell Carcinoma. Urology 2019. [Epub ahead of print].

4. Kavoussi N, Canvasser N, Caddedu J. Ablative Therapies for the Treatment of Small Renal Masses: a Review of Different Modalities and Outcomes. Curr Urol Rep 2016;17:59.

5. Campbell S, Uzzo RG, Allaf ME, et al. Renal Mass and Localized Renal Cancer: AUA Guideline. J Urol 2017;198:520-9.

6. Finelli A, Ismaila N, Bro B, et al. Management of Small Renal Masses: American Society of Clinical Oncology Clinical Practice Guideline. J Clin Oncol 2017;35:668-80.

7. Patel HD, Pierorazio PM, Johnson MH, et al. Renal Functional Outcomes after Surgery, Ablation, and Active 
Surveillance of Localized Renal Tumors: A Systematic

Review and Meta-Analysis. Clin J Am Soc Nephrol 2017;12:1057-69.

8. Rivero JR, De La Cerda J 3rd, Wang H, et al. Partial Nephrectomy versus Thermal Ablation for Clinical Stage T1 Renal Masses: Systematic Review and Meta-Analysis of More than 3,900 Patients. J Vasc Interv Radiol 2018;29:18-29.

9. Pierorazio PM, Johnson MH, Patel HD, et al. Management of Renal Masses and Localized Renal Cancer: Systematic Review and Meta-Analysis. J Urol 2016;196:989-99.

10. Sanchez A, Feldman AS, Hakimi AA. Current Management of Small Renal Masses, Including Patient Selection, Renal Tumor Biopsy, Active Surveillance, and Thermal Ablation. J Clin Oncol 2018;36:3591-600.

11. Caputo PA, Zargar H, Ramirez D, et al. Cryoablation versus Partial Nephrectomy for Clinical T1b Renal Tumors: A Matched Group Comparative Analysis. Eur Urol 2017;71:111-7.

12. Chang X, Zhang F, Liu T, et al. Radio frequency ablation versus partial nephrectomy for clinical $\mathrm{T} 1 \mathrm{~b}$ renal cell carcinoma: long-term clinical and oncologic outcomes. J Urol 2015;193:430-5.

13. Olweny EO, Park SK, Tan YK, et al. Radiofrequency ablation versus partial nephrectomy in patients with solitary clinical T1a renal cell carcinoma: comparable oncologic outcomes at a minimum of 5 years of follow-up.
Eur Urol 2012;61:1156-61.

14. Sung HH, Park BK, Kim CK, et al. Comparison of percutaneous radiofrequency ablation and open partial nephrectomy for the treatment of size- and locationmatched renal masses. Int J Hyperthermia 2012;28:227-34.

15. Thompson RH, Atwell T, Schmit G, et al. Comparison of partial nephrectomy and percutaneous ablation for cT1 renal masses. Eur Urol 2015;67:252-9.

16. Andrews JR, Atwell T, Schmit G, et al. Oncologic Outcomes Following Partial Nephrectomy and Percutaneous Ablation for cT1 Renal Masses. Eur Urol 2019;76:244-51.

17. Camacho JC, Kokabi N, Xing M, et al. R.E.N.A.L. (Radius, exophytic/endophytic, nearness to collecting system or sinus, anterior/posterior, and location relative to polar lines) nephrometry score predicts early tumor recurrence and complications after percutaneous ablative therapies for renal cell carcinoma: a 5-year experience. J Vasc Interv Radiol 2015;26:686-93.

18. Schmit GD, Thompson RH, Kurup AN, et al. Usefulness of R.E.N.A.L. nephrometry scoring system for predicting outcomes and complications of percutaneous ablation of 751 renal tumors. J Urol 2013;189:30-5.

19. Manley BJ, Reznik E, Ghanaat M, et al. Characterizing recurrent and lethal small renal masses in clear cell renal cell carcinoma using recurrent somatic mutations. Urol Oncol 2019;37:12-7.
Cite this article as: Mano R, Hakimi AA. Are the long-term outcomes of percutaneous ablation for clinical stage T1 renal tumors similar to those of partial nephrectomy? Ann Transl Med 2019;7(Suppl 8):S370. doi: 10.21037/atm.2019.08.106 